\title{
Reasonable compensation coefficient of maximum gradient in long railway tunnels
}

\author{
Sirong YI*, Liangtao NIE, Yanheng CHEN, Fangfang QIN \\ School of Civil Engineering, MOE Key Laboratory of High-Speed Railway Engineering, Southwest Jiaotong University, Chengdu \\ 610031, China
}

\begin{abstract}
This paper deals with the theory and calculation methods for compensation of the gradient in railway tunnels through theoretical analysis, numerical calculation, and statistic regression methods. On the basis of the principle that the resultant force is zero, the formula of the maximum calculated gradient was derived for the freight and passenger line and high-speed passenger special line. The formula of aerodynamic drag in tunnel is provided using the domestic and foreign relevant experimental investigations, and revised with modern train and engineering parameters. A calculation model of aerodynamic drag when the train goes through a single-tracked tunnel was built. Finally, the concept of maximum calculated gradient was adopted to revise the formula for compensation of the gradient in railway tunnels.
\end{abstract}

Key words: railway tunnel; maximum gradient; profile; gradient compensation

(C) 2011 JMT. All rights reserved.

\section{Introduction}

$\mathrm{F}$ or freight and passenger lines, at the location where the maximum gradient needs to be used in design, when the train passes through a tunnel of length more than $400 \mathrm{~m}$, its additional resistance increases, but the adhesion coefficient lessens, which leads to the design gradient of the profile plus the equivalent gradient of additional aerodynamic drag in the tunnel being greater than the maximum gradient. Therefore, in the profile design, we need to compensate for the maximum gradient to ensure the general freight train can pass through this location at no less than the stipulated speed. Code for Design of Railway Line (hereinafter referred to as the Line Specification) offers us the maximum gradient compensation coefficients for the corresponding tunnels [1]. However, due to the advancement of railway speed in China, the calculation formula in the existing codes cannot be adapted to the current engineering conditions. In order to revise the principle and parameters of maximum gradient compensation for railway tunnels, we should combine new technical conditions of the railway system to study the theory, method, and compensation model.

Considering the electric railway, this paper will introduce the research achievement on developing a rea-

Received Dec.16, 2010; revision accepted Jan.11, 2011 *Corresponding author. E-mail: sryi@home.swjtu.edu.cn doi: 10.3969/j.issn.2095-087X.2011.01.003 sonable compensation coefficient for the gradient of a long railway tunnel.

\section{Calculation model of maximum gradient of design line}

The maximum calculated gradient of a railway line is defined as the gradient value of the consecutive ascending grade on which a given locomotive can haul the train with a specified weight at the calculated, constant speed of the locomotive.

For freight trains and passenger trains with traction mass of $G$, the maximum calculated gradient of the train is derived based on the principle that the resultant force acting on the train is zero when the freight train runs on a consecutive ascending grade at the specified calculated, constant speed of the locomotive. For a provided traction mass norm, the maximum calculated gradient at the section where the train is hauled by a single locomotive can be calculated as follows [2]:

$$
i_{\text {cmax }}=\frac{\lambda_{\mathrm{u}} F_{\mathrm{c}}-\left(P w_{0}^{\prime}+G w_{0}^{\prime \prime}\right) g}{(P+G) g},
$$

where $G$ is the norm of traction mass, in $\mathrm{t}$; $i_{\text {cmax }}$ is the maximum calculated gradient; $w_{0}{ }^{\prime}$ is unit basic resistance of locomotive under the calculated speed, in $\mathrm{N} / \mathrm{kN}$; $w_{0}{ }^{\prime \prime}$ is unit basic resistance of rolling stock under the calculated speed, in $\mathrm{N} / \mathrm{kN} ; F_{\mathrm{c}}$ is calculated traction force, in $\mathrm{kN}$; $P$ is locomotive mass, in $\mathrm{t} ; \lambda_{\mathrm{u}}$ is utilization coef- 
ficient of traction force; $g$ is acceleration of gravity, in DQt 10.1007/BF03325733

At the section where the maximum gradient needs to be used, if the equivalent gradient of the profile exceeds the maximum gradient, the freight train will eventually run at a speed less than calculated speed on the consecutive ascending grade, which will result in accidents due to the slow speed, even causing a suspension. Hence, the design gradient of the profile plus the equivalent gradient of additional resistance in the tunnel should not be greater than the maximum gradient. Therefore, for the profile design of railway, we need to reduce the maximum gradient to ensure the freight train passes through this section at no less than calculated or stipulated speed.

\subsection{Calculation model of additional aerodynamic drag in single-tracked tunnel}

When a train goes through a double-track tunnel, there is no directional airflow, so the average aerodynamic drag formula cannot be deduced theoretically. In the case of no meeting trains, because the train runs through the tunnel of larger cross section, the blockage ratio becomes greater, and the aerodynamic drag is less than that in the single-track tunnel. In the case of meeting trains in double-track tunnel, through mathematical analysis on the energy and momentum of aerodynamic drag, we can analyze the flow field (velocity field and dynamic pressure field) around the location of the meeting trains of different type and length with different speed, and then calculate the increment of aerodynamic drag.

The paper herein deals with a calculation method of additional aerodynamic drag in single-tracked tunnel.

When a train goes through a single-tracked tunnel, there exists directional airflow in tunnel. Then we can deduce average aerodynamic drag formula theoretically.

Air cannot spread due to being restrained by tunnel when train is running in tunnel, leading the piston phenomenon, i.e. the difference between head positive pressure and tail negative pressure, which produces the resistance to the train. Meanwhile, the turbulent flow in tunnel produces friction between the air and the surface of the train and the tunnel, which also generates the resistance to the train. Therefore, when the train is running in the tunnel, aerodynamic drag acting on the train is far more than that in the open. The aerodynamic drag increment is called additional aerodynamic drag in the tunnel.

In the calculation of aerodynamic drag increment in the tunnel, a series of parameters need to be determined first, such as the frictional resistance coefficient of the train surface, frictional resistance coefficient of tunnel surface, the pressure drag coefficient of the train head and tail, train shape parameters, and tunnel design parameters. These calculation parameters determine the correctness of the result. Especially, the pressure drag coefficient of the train head and tail and the frictional resistance coefficient of the train surface have a great influence on the correctness of the result.

When a train is going through a tunnel, the aerodynamic drag includes three items: pressure drag of the train head, pressure drag of the tail, and surface friction resistance of the body. The key to determining aerodynamic drag when a train passes through a tunnel is to determine the pressure drag coefficient of the train head and tail, surface friction resistance coefficient of the train body and wind speed in the tunnel.

The related studies [3-5] show that additional aerodynamic drag in the tunnel is related to driving speed, length of the train, the superficial area of the train against the air, train shape, tunnel length, area of tunnel cross-section, and tunnel surface roughness. The relation between aerodynamic drag in the tunnel, air pressure difference and tunnel cross-section area can be expressed as follows:

$$
W_{\mathrm{t}}=h F_{\mathrm{t}},
$$

where $F_{\mathrm{t}}$ is the area of tunnel cross-section, for the simplification of calculation, can be taken as the value in Table 1.

Table 1 The minimum effective area of cross-section in tunnel (recommended value in calculation) $\mathrm{m}^{2}$

\begin{tabular}{|c|c|c|c|c|}
\hline \multirow{2}{*}{$\begin{array}{l}\text { Design running } \\
\text { speed of passen- } \\
\text { ger train }(\mathrm{km} / \mathrm{h})\end{array}$} & \multicolumn{2}{|c|}{ Electric traction } & \multicolumn{2}{|c|}{ Diesel Traction } \\
\hline & $\begin{array}{l}\text { Single- } \\
\text { track }\end{array}$ & $\begin{array}{c}\text { Double- } \\
\text { track }\end{array}$ & $\begin{array}{l}\text { Single- } \\
\text { track }\end{array}$ & $\begin{array}{c}\text { Double- } \\
\text { track }\end{array}$ \\
\hline$\leqslant 120$ & 37 & & 31 & \\
\hline$\leqslant 160$ & 42 & 76 & 42 & 76 \\
\hline 200 & 50 & 80 & 50 & 80 \\
\hline 250 & 58 & 90 & 58 & 90 \\
\hline 350 & 70 & 100 & 70 & 100 \\
\hline Remarks & $\begin{array}{r}\text { Without } \\
\text { doub }\end{array}$ & $\begin{array}{l}\text { onsideri } \\
\text {-decked }\end{array}$ & $\begin{array}{l}\text { requires } \\
\text { ntainer }\end{array}$ & $\begin{array}{l}\text { nents of } \\
\text { rains }\end{array}$ \\
\hline
\end{tabular}

Unit aerodynamic drag in the tunnel is

$$
w_{\mathrm{t}}=\frac{h F_{\mathrm{t}}}{(P+G) g},
$$

where $h$ is unit difference of air pressure, in N/m

$$
h=K \frac{\gamma}{2}\left(v-v_{0}\right)^{2},
$$

where $K$ is the effect coefficient of piston pressure:

$$
K=\frac{N L_{\mathrm{tr}}}{\left(1-F_{\mathrm{tr}} / F_{\mathrm{t}}\right)^{2}}=\frac{86 \times 10^{-4} L_{\mathrm{tr}}}{\left(1-F_{\mathrm{tr}} / F_{\mathrm{t}}\right)^{2}},
$$


where $L_{\mathrm{tr}}$ is length of train, in $\mathrm{m}$, and $F_{\mathrm{tr}}$ is area of crossDection of train, taken as $12.6 \mathrm{~m}^{2} ; \gamma$ is the density of air, taken as $1.2 \mathrm{~kg} / \mathrm{m}^{3} ; v$ is speed of train, in $\mathrm{m} / \mathrm{s} ; v_{0}$ is wind speed in piston, in $\mathrm{m} / \mathrm{s}$ :

$$
v_{0}=\frac{v}{1+\sqrt{\zeta_{\mathrm{t}} / K}}
$$

where $\zeta_{\mathrm{t}}$ is total resistance coefficient of tunnel:

$$
\zeta_{\mathrm{t}}=\sum \zeta+\lambda \frac{L_{\mathrm{t}}-L_{\mathrm{tr}}}{d}
$$

where $\sum \zeta$ is the sum of part resistance coefficient at the entrances to the tunnel, taken as $1.5 ; \lambda$ is internal friction coefficient in the tunnel, taken as $0.025 ; L_{\mathrm{t}}$ is length of the tunnel, in $\mathrm{m} ; d$, in $\mathrm{m}$, is equivalent diameter of the tunnel:

$$
d=4 F_{\mathrm{t}} / R_{\mathrm{t}},
$$

where $R_{\mathrm{t}}$ is tunnel perimeter. When design speed is less

$$
\begin{aligned}
& h=K \frac{\gamma}{2}\left(v-v_{0}\right)^{2}=0.05 K \gamma v^{2}\left(1-\frac{1}{1+\sqrt{\zeta_{\mathrm{t}} / K}}\right)^{2}=0.5 K \gamma v^{2}\left(1-\frac{1}{1+\sqrt{\left(1.5+0.025 \frac{L_{\mathrm{t}}-L_{\mathrm{tr}}}{4 F_{\mathrm{t}} / R_{\mathrm{t}}}\right) / K}}\right)^{2}= \\
& 0.5 \frac{0.0086 L_{\mathrm{tr}}}{\left(1-F_{\mathrm{tr}} / F_{\mathrm{t}}\right)^{2}} \gamma v^{2}\left(1-\frac{1}{1+\sqrt{\left(1.5+0.025 \frac{L_{\mathrm{t}}-L_{\mathrm{tr}}}{4 F_{\mathrm{t}} / R_{\mathrm{t}}} /\left(0.0086 L_{\mathrm{tr}} /\left(1-F_{\mathrm{tr}} / F_{\mathrm{t}}\right)^{2}\right)\right.}}\right)^{2}= \\
& 0.0003318 \frac{\gamma L_{\mathrm{tr}} V^{2}}{\left(1-F_{\mathrm{tr}} / F_{\mathrm{t}}\right)^{2}}\left(1-\frac{1}{1+\sqrt{\left(174.419+2.907 \frac{L_{\mathrm{t}}-L_{\mathrm{tr}}}{4 F_{\mathrm{t}} / R_{\mathrm{t}}} /\left(L_{\mathrm{tr}} /\left(1-F_{\mathrm{tr}} / F_{\mathrm{t}}\right)^{2}\right)\right.}}\right)^{2} \text {. }
\end{aligned}
$$

The formula of the unit aerodynamic drag in a tunnel is

$$
\begin{aligned}
w_{\mathrm{t}}= & \frac{h F_{\mathrm{t}}}{(P+G) g}=\frac{0.00003318 \gamma F_{\mathrm{t}}}{\left(1-F_{\mathrm{tr}} / F_{\mathrm{t}}\right)^{2}} \frac{L_{\mathrm{tr}} V^{2}}{(P+G)}\left(1-\frac{1}{1+\sqrt{\left(174.419\left(1-F_{\mathrm{tr}} / F_{\mathrm{t}}\right)^{2}+2.907 \frac{\left(1-F_{\mathrm{tr}} / F_{\mathrm{t}}\right)^{2}}{4 F_{\mathrm{t}} / R_{\mathrm{t}}}\left(L_{\mathrm{t}}-L_{\mathrm{tr}}\right)\right) / L_{\mathrm{tr}}}}\right)^{2}= \\
& \frac{A L_{\mathrm{tr}}}{(P+G)} V^{2}\left(1-\frac{1}{1+\sqrt{\frac{B+C\left(L_{\mathrm{t}}-L_{\mathrm{tr}}\right)}{L_{\mathrm{tr}}}}}\right)^{2},
\end{aligned}
$$

where

$$
\begin{aligned}
& A=\frac{0.00003318 \gamma F_{\mathrm{t}}}{\left(1-F_{\mathrm{tr}} / F_{\mathrm{t}}\right)^{2}}, \\
& B=174.419\left(1-F_{\mathrm{tr}} / F_{\mathrm{t}}\right)^{2}, \\
& C=2.907 \frac{\left(1-F_{\mathrm{tr}} / F_{\mathrm{t}}\right)^{2}}{4 F_{\mathrm{t}} / R_{\mathrm{t}}} .
\end{aligned}
$$

than $160 \mathrm{~km} / \mathrm{h}$, it is taken as $22.5 \mathrm{~m}$ for single-track tunnel, and $31.55 \mathrm{~m}$ for a double-track tunnel. When design speed is in the range of 160 to $200 \mathrm{~km} / \mathrm{h}$, it is taken as $34.5 \mathrm{~m}$ for a double-track tunnel. When design speed is in range of 200 to $250 \mathrm{~km} / \mathrm{h}$, it is $28.0 \mathrm{~m}$ for a singletunnel and $35.0 \mathrm{~m}$ for a double-track tunnel. When speed is in the range of 250 to $350 \mathrm{~km} / \mathrm{h}$, it is track tunnel.

After substitution of the above parameters, the total resistance coefficient in the tunnel is

$$
\zeta_{\mathrm{t}}=\sum \zeta+\lambda \frac{L_{\mathrm{t}}-L_{\mathrm{tr}}}{d}=1.5+0.025 \frac{L_{\mathrm{t}}-L_{\mathrm{tr}}}{4 F_{\mathrm{t}} / R_{\mathrm{t}}} .
$$

According to the above parameters, the calculation formula of unit air pressure difference can be deduced as follows. 
train passes through this tunnel with no less than the Dalculated speed of the locomotive.

Only the additional aerodynamic drag in the tunnel affects the compensation of maximum gradient for the tunnel when using electric traction. For diesel-traction, however, not only the additional tunnel aerodynamic drag, but also the speed of train through the tunnel influences the compensation of maximum gradient.

Let the compensation of maximum gradient in the tunnel be $\Delta i_{\mathrm{t}}$. Then the maximum design gradient of tunnel, $i(\%)$, is

$$
i=i_{\max }-\Delta i_{\mathrm{t}} \text {. }
$$

In order to simplify the calculation, the maximum gradient compensation value for the tunnel, $\Delta i_{\mathrm{t}}$, can be converted to maximum gradient coefficient $\beta_{\mathrm{t}}$. The relationship of $\beta_{\mathrm{t}}$ with design grade $i$ is as follows:

$$
i=i_{\max }-\Delta i_{\mathrm{t}}=\left(1-\frac{\Delta i_{\mathrm{t}}}{i_{\max }}\right) i_{\max }=\beta_{\mathrm{t}} i_{\max } .
$$

For electric traction

$$
\beta_{\mathrm{t}}= \begin{cases}1-\frac{w_{\mathrm{t}}-\left(i_{\mathrm{c}}-i_{\max }\right)}{i_{\text {max }}}=\frac{i_{\mathrm{c}}-w_{\mathrm{t}}}{i_{\text {max }}}, & i_{\mathrm{c}}-i_{\max } \leq w_{\mathrm{t}}, \\ 1, & i_{\mathrm{c}}-i_{\max }>w_{\mathrm{t}} .\end{cases}
$$

For diesel-traction

$$
\beta_{\mathrm{t}}= \begin{cases}1-\frac{w_{\mathrm{t}}-\left(i_{v}-i_{\max }\right)}{i_{\max }}=\frac{i_{v}-w_{\mathrm{t}}}{i_{\max }}, & i_{v}-i_{\max } \leq w_{\mathrm{t}}, \\ 1, & i_{v}-i_{\max }>w_{\mathrm{t}},\end{cases}
$$

where $w_{\mathrm{t}}$ is additional aerodynamic drag in tunnel, in $\mathrm{N} / \mathrm{kN} ; i_{\max }$ is maximum gradient of design line (\%o); $i_{\mathrm{c}}$ is calculated gradient of locomotive, namely the gradient value when the train runs at a constant speed (for the freight train, it refers to the equilibrium gradient when the locomotive runs at a minimum calculated speed $(\%)) ; i_{v}$ is the equilibrium gradient under the train speed through the tunnel, and it equals the unit resultant force value under the train speed through the tunnel, i.e., $i_{v}=f$ $w_{0}$, where $f$ is unit traction force and $w_{0}$ is the unit basic resistance.

\section{Maximum calculated gradient in bright line section (outside of tunnel)}

\subsection{Relationship between traction mass and calculated gradient for several types of freight locomotives}

According to the calculation, the relationship between traction mass and calculated gradient for several types of freight locomotives (SS1, SS3, SS4, SS7, 6K,
$8 \mathrm{G})$ is shown in Fig. 1. The relationship is decreasing quintic function; namely, the adapted calculated gradient decreases by quintic function with the increase in the traction mass.

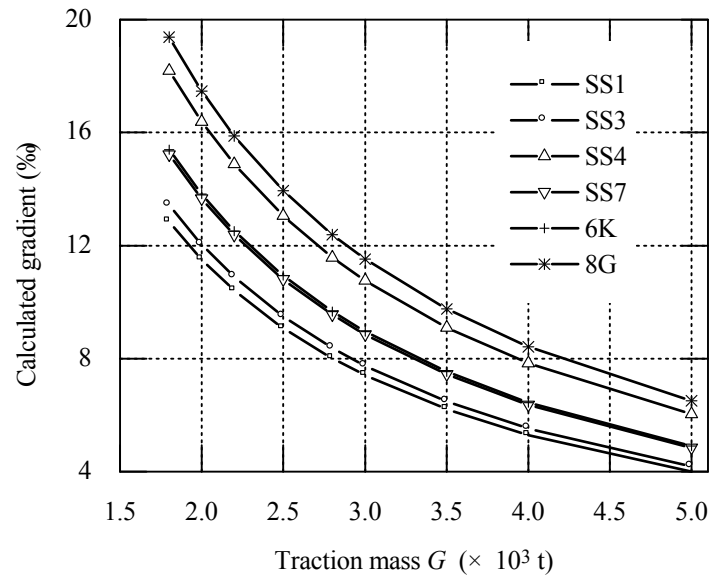

Fig. 1 The relationship between traction mass and calculated gradient for six types of locomotives

\subsection{Surplus value of traction power of electric locomo- tive for ruling gradients}

For the railway of freight and passenger lines hauled by electric locomotive in our country, the ruling gradient should not be greater than values in Table 2 .

Table 2 Maximum ruling gradient value $\quad \%$

\begin{tabular}{cccc}
\hline \multirow{2}{*}{$\begin{array}{c}\text { Classification } \\
\text { of railways }\end{array}$} & \multicolumn{3}{c}{ Terrain type } \\
\cline { 2 - 4 } & Plain & Hilly land & Mountainous area \\
\hline I & 6.0 & 12.0 & 15.0 \\
II & 6.0 & 15.0 & 20.0 \\
III & 9.0 & 18.0 & 25.0 \\
\hline
\end{tabular}

At present, most of railways for freight trains and passenger trains in China employ the ruling gradient of $6 \%$, $9 \%$, or $12 \%$. The surplus of traction force of electric locomotive on the corresponding ruling grade is shown in Table 3 , where $i_{\mathrm{r}}$ is ruling gradient.

\subsection{Comprehensive analysis of dynamic characteristics for a freight train running on ascending grade}

Table 3 shows that, for freight train and passenger train using locomotives SS4, SS7, 8K and 6G, when traction mass are 1800 and $2000 \mathrm{t}$, trains can run on the grade with the ruling gradient of no more than $15 \%$ at certain accelerated speed. When traction mass is $1800 \mathrm{t}$, the accelerated allowance of locomotive SS4 is greater than the maximum compensation of gradient in the tun- 


\begin{tabular}{|c|c|c|c|c|c|c|c|c|c|c|c|c|}
\hline \multirow{2}{*}{$\begin{array}{l}\text { Locomo- } \\
\text { tive } \\
\text { type }\end{array}$} & \multicolumn{12}{|c|}{ Traction mass/ruling gradient } \\
\hline & $\begin{array}{l}1800 \\
/ 15\end{array}$ & $\begin{array}{l}2000 \\
/ 15\end{array}$ & $\begin{array}{c}1800 \\
/ 12\end{array}$ & $\begin{array}{l}2000 \\
/ 12\end{array}$ & $\begin{array}{c}2500 \\
19\end{array}$ & $\begin{array}{c}2800 \\
19\end{array}$ & $\begin{array}{l}3000 \\
\quad / 6\end{array}$ & $\begin{array}{c}3500 \\
16\end{array}$ & $\begin{array}{l}4000 \\
16\end{array}$ & $\begin{array}{l}5000 \\
16\end{array}$ & $\begin{array}{c}4000 \\
/ 4\end{array}$ & $\begin{array}{l}5000 \\
\quad / 4\end{array}$ \\
\hline $\mathrm{SS} 1$ & -2.16 & -3.49 & 0.84 & -0.49 & 0.07 & -0.99 & 1.41 & 0.21 & -0.71 & -2.0 & 1.29 & 0.0 \\
\hline $\mathrm{SS} 3$ & -1.57 & -2.96 & 1.43 & 1.04 & 0.49 & -0.63 & 1.74 & 0.48 & -0.47 & -1.83 & 1.53 & 0.17 \\
\hline SS4 & 3.18 & 1.38 & 6.18 & 4.38 & 4.05 & 2.58 & 4.76 & 3.10 & 1.83 & 0.03 & 3.83 & 2.03 \\
\hline SS7 & 0.22 & -1.34 & 3.22 & 1.66 & 1.8 & 1.59 & 2.85 & 1.44 & 0.36 & -1.52 & 2.36 & 0.84 \\
\hline $6 \mathrm{~K}$ & 0.39 & -1.18 & 3.39 & 1.82 & 1.93 & 0.66 & 2.96 & 1.53 & 0.44 & -1.09 & 2.44 & 0.91 \\
\hline $8 \mathrm{G}$ & 4.38 & 2.47 & 7.38 & 5.47 & 4.94 & 3.39 & 5.52 & 3.76 & 2.42 & 0.51 & 4.42 & 2.51 \\
\hline \multirow{3}{*}{$\left(1-\beta_{\mathrm{t}}\right) i_{\mathrm{r}}$} & \multicolumn{2}{|c|}{$\begin{array}{c}0.75 \text { for } \\
400<L_{t}<1000\end{array}$} & \multicolumn{2}{|c|}{$\begin{array}{c}0.6 \text { for } \\
400<L_{\mathrm{t}}<1000\end{array}$} & \multicolumn{2}{|c|}{$\begin{array}{c}0.45 \text { for } \\
400<L_{\mathrm{t}}<1000\end{array}$} & \multicolumn{4}{|c|}{0.3 for $400<L_{\mathrm{t}}<1000$} & \multicolumn{2}{|c|}{$\begin{array}{c}0.2 \text { for } \\
400<L_{\mathrm{t}}<1000\end{array}$} \\
\hline & \multicolumn{2}{|c|}{$\begin{array}{c}1.5 \text { for } \\
1000<L_{\mathrm{t}}<4000\end{array}$} & \multicolumn{2}{|c|}{$\begin{array}{c}1.2 \text { for } \\
1000<L_{t}<4000\end{array}$} & \multicolumn{2}{|c|}{0.9 for $1000<L_{\mathrm{t}}<4000$} & \multicolumn{4}{|c|}{0.6 for $1000<L_{\mathrm{t}}<4000$} & \multicolumn{2}{|c|}{$\begin{array}{c}0.4 \text { for } \\
1000<L_{\mathrm{t}}<4000\end{array}$} \\
\hline & \multicolumn{2}{|c|}{2.25 for $4000<L_{\mathrm{t}}$} & \multicolumn{2}{|c|}{1.8 for $4000<L_{\mathrm{t}}$} & \multicolumn{2}{|c|}{1.35 for $4000<L_{\mathrm{t}}$} & \multicolumn{4}{|c|}{0.9 for $4000<L_{\mathrm{t}}$} & \multicolumn{2}{|c|}{0.6 for $4000<L_{\mathrm{t}}$} \\
\hline
\end{tabular}

nel. In the railway of plain and hilly regions, in the case of locomotives SS1 and SS3 at $1800 / 12,2500 / 9$, $3000 / 6$, and $3500 / 6$ (trailing load/ruling gradient), the calculated gradient is greater than the corresponding ruling gradient, and the locomotives run at the calculated speed with a certain acceleration allowance. In the remaining calculation conditions, except for $3000 / 6$, the allowance is always less than the corresponding compensation of gradient in tunnel in the current Line Specifications [1]. Hence, when using electric locomotives SS1 and SS3, we should take the compensation of maximum gradient in the tunnel into consideration to ensure that the locomotive hauls the train with no less than the calculated speed through this tunnel. When the traction mass is $5000 \mathrm{t}$, on the grade with $6 \%$ gradient, train can run at the calculated, constant speed of the locomotive with a certain acceleration allowance, but the allowance is less than the compensation of gradient in tunnel. When traction mass is less than $5000 \mathrm{t}$, in the case of locomotives SS4, SS7, 6K and $8 \mathrm{G}$ running on the grade with gradient of $6 \%$, $9 \%$ and $12 \%$, calculated gradient are all more than the ruling gradient, and the traction force is surplus.

The above analysis shows that for different ruling gradient and corresponding traction mass, we can ensure the locomotive hauls the train to run with certain acceleration allowance on limiting ascending grade by properly choosing electric locomotive.

For high-power electric locomotives SS4, SS7, 6K, $8 \mathrm{G}$, etc., according to the current Line Specifications, even in a tunnel section, locomotives still are able to pass through at no less than the calculated speed with certain acceleration allowance.

\section{Model of relationship between aerody- namic drag in tunnel and train speed}

When trains with the same traction mass pass through tunnels with the same length, aerodynamic drag in tunnel is in direct proportion to the square of train speed. As the length difference among different types of locomotives is tiny, aerodynamic drags in a tunnel are very close, tending to the same quadratic curve. Therefore, when the norm of traction mass is certain, the aerodynamic drag in a tunnel can be regressed to the uniform calculation formula. Table 4 provides the relationship of the aerodynamic drag in a tunnel and the speed $(V)$ of the train with traction mass of $4000 \mathrm{t}$.

Table 4 General formula of aerodynamic drag of electric traction freight train with $4000 \mathrm{t}$ traction mass in tunnel

\begin{aligned} & \hline$L_{\mathrm{t}}(\mathrm{m}) w_{\mathrm{t}} \\ &$\hline 1000$w_{\mathrm{t}}=0.55 \mathrm{~V}^{2} \times 10^{-4}+0.331 \mathrm{~V} \times 10^{-5}+0.0000496 \\ & 5000 w_{\mathrm{t}}=1.66 V^{2} \times 10^{-4}+0.998 \mathrm{~V} \times 10^{-5}+0.001497 \\ & 10000 w_{\mathrm{t}}=2.265 \mathrm{~V}^{2} \times 10^{-4}+0.136 \mathrm{~V} \times 10^{-5}+0.000102 \\ & 15000 w_{\mathrm{t}}=2.63 \mathrm{~V}^{2} \times 10^{-4}+0.1579 \mathrm{~V} \times 10^{-5}+0.0002369 \\ & 20000 w_{\mathrm{t}}=2.89 \mathrm{~V}^{2} \times 10^{-4}+0.1735 \mathrm{~V} \times 10^{-5}+0.0001301 \\ & 25000 w_{\mathrm{t}}=3.088 \mathrm{~V}^{2} \times 10^{-4}+0.1854 \mathrm{~V} \times 10^{-5}+0.000139 \\ & 30000 w_{\mathrm{t}}=3.245 \mathrm{~V}^{2} \times 10^{-4}+0.1949 \mathrm{~V} \times 10^{-5}+0.0002924 \\ &$\hline\end{aligned}

\section{Maximum aerodynamic drag in tunnel}

According to Table 4, we can calculate the aerodynamic drag for different electric locomotive when it 
passes through the tunnel at the calculated speed. TaBle 5 shiows the a 1025733 amic drag in a tunnel when locomotives SS4 and SS7 haul trains through the tunnel with different length.

\section{Comprehensive analysis}

6.1. Comparison between calculated gradient and aerodynamic drag in tunnel

According to above analysis, Table 6 shows the relationship between acceleration allowance and aerody- namic drag in a tunnel when the electric locomotives run with calculated speed on ruling grade.

Comprehensive analysis for Tables 5 and 6, and Fig. 1 shows that when using locomotives SS4, SS7, 8K, and $6 \mathrm{G}$ and traction mass is 1800 or $2000 \mathrm{t}$, the trains could run on the grade with the ruling gradient of no more than $15 \%$ at certain acceleratedspeed. When traction mass is $1800 \mathrm{t}$, acceleration allowance of locomotive SS4 is greater than the maximum compensation of gradient in the tunnel. For the railway in plain and hilly in the case of locomotives SS1 and SS3 at $1800 / 12$, $2500 / 9,3000 / 6$, and $3500 / 6$, the calculated gradient is

Table 5 Aerodynamic drag in a tunnel when an electric traction freight train passes through at the calculated speed N/kN

\begin{tabular}{|c|c|c|c|c|c|c|}
\hline \multirow{2}{*}{$L(\mathrm{~m})$} & \multirow{2}{*}{ Locomotive type } & \multicolumn{4}{|c|}{$G(\mathrm{t})$} & \multirow{2}{*}{$\begin{array}{l}\text { Passenger } \\
\text { train }\end{array}$} \\
\hline & & 3000 & 3500 & 4000 & 5000 & \\
\hline \multirow{2}{*}{1000} & SS4 & 0.195231 & 0.164893 & 0.138807 & 0.095333 & 0.494253 \\
\hline & SS7 & 0.172301 & 0.145636 & 0.122741 & 0.084656 & 0.434538 \\
\hline \multirow{2}{*}{5000} & SS4 & 0.452779 & 0.417774 & 0.387635 & 0.337852 & 1.212022 \\
\hline & $\mathrm{SS} 7$ & 0.395471 & 0.364854 & 0.338499 & 0.294980 & 1.065321 \\
\hline \multirow{2}{*}{10000} & SS4 & 0.664143 & 0.627960 & 0.596365 & 0.543296 & 1.592419 \\
\hline & $\mathrm{SS} 7$ & 0.578286 & 0.546814 & 0.519313 & 0.473097 & 1.399675 \\
\hline \multirow{2}{*}{15000} & SS4 & 0.760329 & 0.724740 & 0.693443 & 0.640411 & 1.818034 \\
\hline & SS7 & 0.661349 & 0.630485 & 0.603312 & 0.557220 & 1.595986 \\
\hline \multirow{2}{*}{20000} & $\mathrm{SS} 4$ & 0.827564 & 0.792828 & 0.762129 & 0.709781 & 1.975440 \\
\hline & S7 & 0.719361 & 0.689307 & 0.662704 & 0.617278 & 1.736336 \\
\hline \multirow{2}{*}{25000} & SS4 & 0.878547 & 0.844700 & 0.814674 & 0.763226 & 2.096116 \\
\hline & SS7 & 0.763323 & 0.734095 & 0.708118 & 0.663531 & 1.842405 \\
\hline \multirow{2}{*}{30000} & SS4 & 0.923000 & 0.891600 & 0.856700 & 0.806200 & 2.190327 \\
\hline & SS7 & 0.801800 & 0.774100 & 0.744200 & 0.700400 & 1.925199 \\
\hline
\end{tabular}

Table 6 Comparison between surplus value of traction force and aerodynamic drag in a tunnel when the electric locomotive runs on ruling grade

$\mathrm{N} / \mathrm{kN}$

\begin{tabular}{|c|c|c|c|c|c|c|c|c|}
\hline \multirow{2}{*}{$\begin{array}{l}\text { Locomotive } \\
\text { type }\end{array}$} & \multicolumn{8}{|c|}{ Traction mass/ruling gradient } \\
\hline & $3000 / 9$ & $3500 / 9$ & $3000 / 6$ & $3500 / 6$ & $4000 / 6$ & 5 000/6 & $4000 / 4$ & $5000 / 4$ \\
\hline SS1 & & & 1.41 & 0.21 & & -2.0 & 1.29 & 0.0 \\
\hline SS3 & & & 1.74 & 0.48 & & -1.83 & 1.53 & 0.17 \\
\hline SS4 & 1.76 & 0.10 & 4.76 & 3.10 & 1.83 & 0.03 & 3.83 & 2.03 \\
\hline SS7 & & & 2.85 & 1.44 & 0.36 & -1.52 & 2.36 & 0.84 \\
\hline $6 \mathrm{~K}$ & & & 2.96 & 1.53 & 0.44 & -1.09 & 2.44 & 0.91 \\
\hline $8 \mathrm{G}$ & 2.52 & 0.76 & 5.52 & 3.76 & 2.42 & 0.51 & 4.42 & 2.51 \\
\hline$W_{\mathrm{t}}$ & \multicolumn{3}{|c|}{$\begin{array}{l}0.20 \text { for } 400<L_{\mathrm{t}}<1000 \\
0.75 \text { for } 10001<L_{\mathrm{t}}<15000\end{array}$} & $\begin{array}{l}0.45 \text { for } \\
0.85 \text { for } \\
0.95 \text { for }\end{array}$ & $\begin{array}{l}1<L_{\mathrm{t}}<5 \\
01<L_{\mathrm{t}}<2 \\
01<L_{\mathrm{t}}<3\end{array}$ & \multicolumn{3}{|c|}{$\begin{array}{l}0.65 \text { for } 5001<L_{\mathrm{t}}<10000 \\
0.90 \text { for } 20001<L_{\mathrm{t}}<25000\end{array}$} \\
\hline
\end{tabular}


greater than the corresponding ruling gradient, and the POCI: 10t1007/BF03325733 3 lated speed with a certain acceleration allowance. However, in the rest calculation conditions except for $3000 / 6$, the allowance is always less than the gradient compensation for corresponding tunnel in the current Line Specifications. For example, when using electric locomotives SS1, SS3, we should take the compensation of maximum gradient in the tunnel into consideration to ensure that the locomotive hauls train with no less than calculated speed through this tunnel. When traction mass is $5000 \mathrm{t}$, train can run on $6 \%$ grade at the calculated speed of locomotive constantly with a certain acceleration allowance, but the allowance is less than the compensation of gradient in tunnel. When traction mass is less than $5000 \mathrm{t}$ and using locomotives SS4, SS7, $6 \mathrm{~K}$, and $8 \mathrm{G}$ to haul train on the ruling grade of $6 \%, 9 \%$, and $12 \%$, the calculated gradient is more than the ruling gradient, and the allowance is greater than the equivalent gradient of the aerodynamic drag in the tunnel.

\subsection{Comparison between calculated aerodynamic drag and compensation of gradient in a tunnel in current Line Specifications}

Table 7 shows the compensation of gradient in tunnel in current Line Specifications and the calculated aerodynamic drag in tunnel.

The comparison of the calculated value with compensation value in current line specifications shows that for the electric traction lines with the ruling gradients of $6 \%$, $9 \%$, and $12 \%$, when the tunnel length is less than $20000 \mathrm{~m}$, calculated value is not more than the aerodynamic drag in the tunnel when $L_{\mathrm{t}}>4000 \mathrm{~m}$ that is stipulated in the current Line Specifications.

Table 7 Comparison between calculated aerodynamic drag and compensation for gradient in a tunnel in current Line Specifications N/kN

\begin{tabular}{|c|c|c|c|}
\hline \multirow{2}{*}{$\begin{array}{l}\text { Ruling } \\
\text { gradient } \\
\quad(\% \text { ) }\end{array}$} & \multicolumn{3}{|c|}{ Length of tunnel (m) } \\
\hline & $400<L_{\mathrm{t}} \leqslant 1000$ & $1000<L_{\mathrm{t}} \leqslant 4000$ & $L_{\mathrm{t}}>4000$ \\
\hline 15 & 0.75 & 1.5 & 2.25 \\
\hline 12 & 0.6 & 1.2 & 1.8 \\
\hline 9 & 0.45 & 0.9 & 1.35 \\
\hline 6 & 0.3 & 0.6 & 0.9 \\
\hline $\begin{array}{l}\text { Calculated } \\
\text { aerodynamic } \\
\text { drag }\end{array}$ & \multicolumn{3}{|c|}{$\begin{array}{l}L_{\mathrm{t}}=20001-25000: 0.90 ; \\
L_{\mathrm{t}}=25001-30000: 0.95\end{array}$} \\
\hline
\end{tabular}

\section{Conclusions}

(1) For the different ruling gradient and traction mass, we can properly choose the locomotive from the current electric traction locomotives in China to ensure the locomotive hauls train to run on limiting ascending grade with certain acceleration allowance. The high-power electric locomotives SS4, SS7, 6K, 8G, etc., even in tunnel location, still run at no less than the calculated speed with certain acceleration allowance through the tunnel.

(2) In the electric traction railway for freight and passenger lines, when passenger train is passing tunnel, locomotive traction allowance is greater than the increment of aerodynamic drag in tunnel. Therefore, the design of maximum gradient of tunnel is not affected by the passenger train.

(3) In the design of railway for freight train and passenger train, the influence of aerodynamic drag should be taken into account when a fast-speed passenger train passes through a tunnel. The calculation results of this paper show that when trains have the same length and outside shape, for the same type of locomotive, if the traction mass is less, the unit aerodynamic drag is greater. For the same traction mass, if the calculated speed is greater, the aerodynamic drag in tunnel is greater. For electrical freight locomotive, the calculated speed of locomotive SS4 is the greatest, i.e. $51.2 \mathrm{~km} / \mathrm{h}$, and accordingly its aerodynamic drag in tunnel is the greatest. According to the above analysis, for electric traction, calculation of aerodynamic drag in tunnel can be divided into seven grades: 401-1 000, 1 001-5 000, 5 001-10 000, 10 001-15000, 15 001-20 000, $20001-$ 25000 , and 25001-30000, the corresponding additional aerodynamic drag can be calculated in terms of $0.20,0.45,0.65,0.75,0.85,0.90$, and $0.95 \mathrm{~N} / \mathrm{kN}$, respectively.

\section{References}

[1] The Ministry of Railway of the People's Republic of China, Code for Design of Railway Line, Beijing: China Planning Press, 2006.

[2] S.R. Yi, Railway Location Design (the third version), Chengdu: Southwest Jiaotong University Press, 2009.

[3] Y. Hao, Railway Location Design, Beijing: China Railway Publishing House, 1978.

[4] C.J. Baker, S. Dalley, J. Johnson, et al., The slipstream and wake of a high-speed train, Proceedings of the Institution of Mechanical Engineers, Part F: Journal of Rail and Rapid Transit, 2001, 215(2): 83-99.

[5] H.Q. Tian, Train Aerodynamics, Beijing: China Railway Publishing House, 2007. 